\title{
Effects of Chlorpyrifos on Serine Hydrolase Activities, Lipid Mediators, and Immune Responses in Lungs of Neonatal and Adult Mice
}

Brittany N. Szafran ${ }^{1}$, Abdolsamad Borazjani ${ }^{1}$, Caitlin N. Seay ${ }^{1}$, Russell L. Carr ${ }^{1}$, Richard Lehner $^{2}$, Barbara L.F. Kaplan ${ }^{1 *}$, and Matthew K. Ross ${ }^{1 *}$

${ }^{1}$ Department of Comparative Biomedical Sciences, Center for Environmental Health Sciences, College of Veterinary Medicine, Mississippi State University, Mississippi State, MS, 39762, USA.

${ }^{2}$ Departments of Cell Biology and Pediatrics, Group on Molecular \& Cell Biology of Lipids, University of Alberta, Edmonton, AB, Canada.

*corresponding authors (mross@cvm.msstate.edu; bkaplan@cvm.msstate.edu) 


\section{SUPPORTING INFORMATION}

Table S1. Commercial Primers and Mouse Primer Sequences Used for RT-qPCR Analysis

Figure S1. Gating strategy used to identify adaptive and innate cells in the lung. (A) T helper cells were identified as CD4+, cytotoxic T cells as CD8+, and B cells as CD19+. (B) Natural Killer (NK) cells were identified as CD49+/CD11b-, alveolar macrophages (AMs) as F4/80+/CD11c+/CD11b-, monocytes (Mono) as F4/80+/CD11b+/Gr1-, dendritic cells (DCs) as $\mathrm{CD} 11 \mathrm{~b}+/ \mathrm{CD} 11 \mathrm{c}+$, and neutrophils (Neu) as CD11b+/CD11c-/Gr1+.

Figure S2. Daily mouse weights during the treatment regimen with CPF or vehicle. Mice were weighed every day before oral treatment with CPF. Weights of adult mice ( $\mathrm{n}=5 ; \mathrm{AM}=$ Adult Male, AF = Adult Female) (A) and neonatal mice treated from PND 10-16 ( $\mathrm{n}=4-5)$ (B) or PND 4-10 ( $n=8-9)(C)$ are presented. Weights are expressed as mean \pm SD. No significant differences were noted.

Figure S3. AChE activities of brain and lung. AChE activity was measured in the brain of neonatal (A) and adult female (B) mice. AChE activity was also measured in the brains of WT and Ces $1 d^{-/}$neonates (C) and adult males (D) in the setting of LPS-induced inflammation. AChE $(\mathrm{E}, \mathrm{G})$ and $\mathrm{BChE}(\mathrm{F}, \mathrm{H})$ activities of lung microsomes and cytosols were also determined. Specific activities were calculated as nmoles of product $\min ^{-1} \mathrm{mg}$ protein ${ }^{-1}$. Data are expressed as mean $\pm \mathrm{SD}(\mathrm{n}=4-5)$. Significant differences are noted two-way ANOVA and Tukey multiple comparison test.

Figure S4. Gel-based ABPP and western blots of neonate and adult lungs. (A) To determine whether Ces1 proteins were affected by in vivo CPF treatments, lung proteomes were treated with the activity probe FP-biotin ( $1 \mathrm{~h}, 8 \mu \mathrm{M}$, room temperature) and separated by SDS-PAGE. Biotin-labeled proteins were detected with avidin-HRP after transfer of proteins to a PVDF membrane. The membrane was then stripped and re-probed with a human CES1 antibody to detect Ces1 isoforms, which migrate to the same position in gels because each have molecular weights $\sim 60 \mathrm{kDa}$. The ABPP blot detects 'active' serine hydrolases, whereas the western blot assesses the total abundance of Ces1 isoforms (which cannot be resolved on the gel because of their similar molecular weights). The results include one representative neonate (treated from PND 10-16) and adult female lung sample from each experimental group. (B) Gel-based ABPP 
of adult lung microsomes were titrated with increasing concentrations of $\mathrm{CPO}\left(30 \mathrm{~min}, 37^{\circ} \mathrm{C}\right)$ before treatment with a fixed amount of the activity probe FP-TAMRA $(0.2 \mu \mathrm{M})$. The graph indicates the intensity of the Ces1 gel band as a function of CPO concentration $\left(\mathrm{IC}_{50}=77 \mathrm{nM}\right)$.

Figure S5. Innate and adaptive immunophenotypes in WT and Ces $1 d^{-/-}$mouse lungs determined by flow cytometry. Cells were identified as T helper cells (CD4+), cytotoxic T cells (CD8+), B cells (CD19+), natural killer cells (NK, CD49+, CD11b-), alveolar macrophages (AM, F4/80+, CD11c+, CD11b-), monocytes (MONO, F4/80+, CD11b+, Gr1-), dendritic cells (DC, CD11b+, CD11c+), or neutrophils (NEU, CD11b+, CD11c-, Gr1+) in neonatal (A,C, n=5) and adult male $(B, D, n=4)$ mice. Data are expressed as the mean of percent lymphocyte gated \pm SD. Data were analyzed utilizing a two-way ANOVA and Tukey multiple comparisons test; ${ }^{*} \mathrm{p}<0.05$ compared to saline controls, $\# \mathrm{p}<0.05$ indicated comparison.

Figure S6. Cytokine mRNA and protein levels in WT lungs determined by RT-qPCR and ELISA. RNA was extracted from the right middle lung lobe and reverse transcribed to measure $I l 1 \beta$, Il6, and Tnf $\alpha$ mRNA from neonatal mice $(\mathrm{n}=10-13)(\mathrm{A})$, adult male mice $(\mathrm{n}=15)(\mathrm{B})$, and adult female mice $(n=5)(C)$. Protein from the left lung lobe was extracted and a sandwich-based ELISA assay used to measure IL-1 $\beta$, IL-6, and TNF- $\alpha$ protein from neonatal mice (n=9-13) (D) and adult male mice $(n=15)(E)$. IL-6 was measured by ELISA in adult female mice $(n=5)(F)$. Data are expressed as mean \pm SD. Data were analyzed utilizing a two-way ANOVA and Tukey multiple comparisons test; ${ }^{*} \mathrm{p}<0.05$ relative to saline controls.

Figure S7. Cytokine and Ces isoform mRNA levels were quantified in mouse pulmonary alveolar macrophages by RT-qPCR. Macrophages were treated ex vivo with LPS (100 ng/mL, $24 \mathrm{~h}$ ) or vehicle (saline, $24 \mathrm{~h})$. Data are expressed as mean $\pm \mathrm{SD}(\mathrm{n}=2-3)$; ${ }^{*} \mathrm{p}<0.05$. n.d., not detected (cycle threshold, $\mathrm{C}_{\mathrm{t}}>36$ ).

Figure S8. Lung surfactant protein mRNA levels determined by RT-qPCR. RNA was extracted from the right middle lung lobe and reverse transcribed to measure genes that encode lung surfactant proteins A (Sftpal), B (Sftpb), C (Sftpc), and D (Sftpd) in neonatal mice (n=6-9) (A) and adult male mice ( $\mathrm{n}=9-10)(\mathrm{B})$. In neonatal mice, data are compared to WT vehicle/saline controls. In adult male mice, data are compared to Ces $1 d^{-/-}$vehicle/saline controls. mRNA data are expressed in average fold-changes compared to vehicle/saline control. Data are expressed as 
mean \pm SD. Data were analyzed utilizing a two-way ANOVA and Tukey multiple comparisons test; $* \mathrm{p}<0.05$.

Figure S9. Lung lipid mediators were quantified by targeted LC-MS/MS. The right superior lung lobe was extracted as described in the Experimental Section and lipid mediators quantified by the isotope dilution approach using deuterated standards. The indicated lipid mediators in neonatal mice $(n=10-13)(A)$ and adult male mice $(n=15)(B)$ were assessed. In a separate cohort of mice, lipid mediator levels were determined in WT and Ces $1 d^{-/}$neonatal mice $(\mathrm{n}=5)(\mathrm{C})$ and adult male mice (n=4) (D). In neonatal Ces $1 d^{-/}$mice, data are compared to WT vehicle/saline controls. In adult male Ces $1 d^{-/-}$mice, data are compared to Ces $1 d^{-/-}$vehicle/saline controls. Data are expressed as mean \pm SD. Data were analyzed utilizing a two-way ANOVA and Tukey multiple comparisons test; ${ }^{*} \mathrm{p}<0.05$ compared to saline controls, $\# \mathrm{p}<0.05$ indicated comparison. 
Table S1. Commercial Primers and Mouse Primer Sequences Used for RT-qPCR Analysis

\begin{tabular}{|c|c|c|}
\hline $\begin{array}{l}\text { Quantitect } \\
\text { Primers }\end{array}$ & & \\
\hline Gapdh & Mm_Gapdh_3_SG QuantiTect Pr & 58692 \\
\hline$\| 1 b$ & $M m_{-} \| 1 b_{2} 2 \_s G$ QuantiTect Prim & \\
\hline 116 & Mm_II6_1_SG QuantiTect Primeı & \\
\hline Tnfa & Mm_Tnf_1_SG QuantiTect Prime & \\
\hline sftpa & Mm_sftpa1_1_SG QuantiTect Pr & 30200 \\
\hline sftpb & Mm_sftpb_1_SG QuantiTect Prir & 4908 \\
\hline sftpc & Mm_Sftpc_1_SG QuantiTect Prin & 424 \\
\hline sftpd & Mm_Sftpd_1_SG QuantiTect Prir & 4020 \\
\hline $\begin{array}{l}\text { Gene } \\
\text { (mouse) }\end{array}$ & 5'-Forward Sequence-3' & 5'-Reverse Sequence-3' \\
\hline Gapdh & AGGTCGGTGTGAACGGATTTG & TGTAGACCATGTAGTTGAGGTCA \\
\hline$\| 1 b$ & GCAACTGTTCCTGAACTCAACT & ATCTTTTGGGGTCCGTCAACT \\
\hline 116 & TAGTCCTTCCTACCCCAATTTCC & TTGGTCCTTAGCCACTCCTTC \\
\hline Tnfa & СССTCACACTCAGATCATCTTCT & GCTACGACGTGGGCTACAG \\
\hline Ces1c & CTCAGATATGTTCAGCACCGAAA & GCTTTTTGTCAAATCGGCAGG \\
\hline Ces1d & ATATGGCTTTCTCTTGCTGCG & CCCAGGACTTTGCCTTTAACAGT \\
\hline Ces2g & TCTCTGAGGTGGTTTACCAAACG & СCTCTCAGACAGCGCACCAG \\
\hline
\end{tabular}




\section{Supplementary Figure 1}
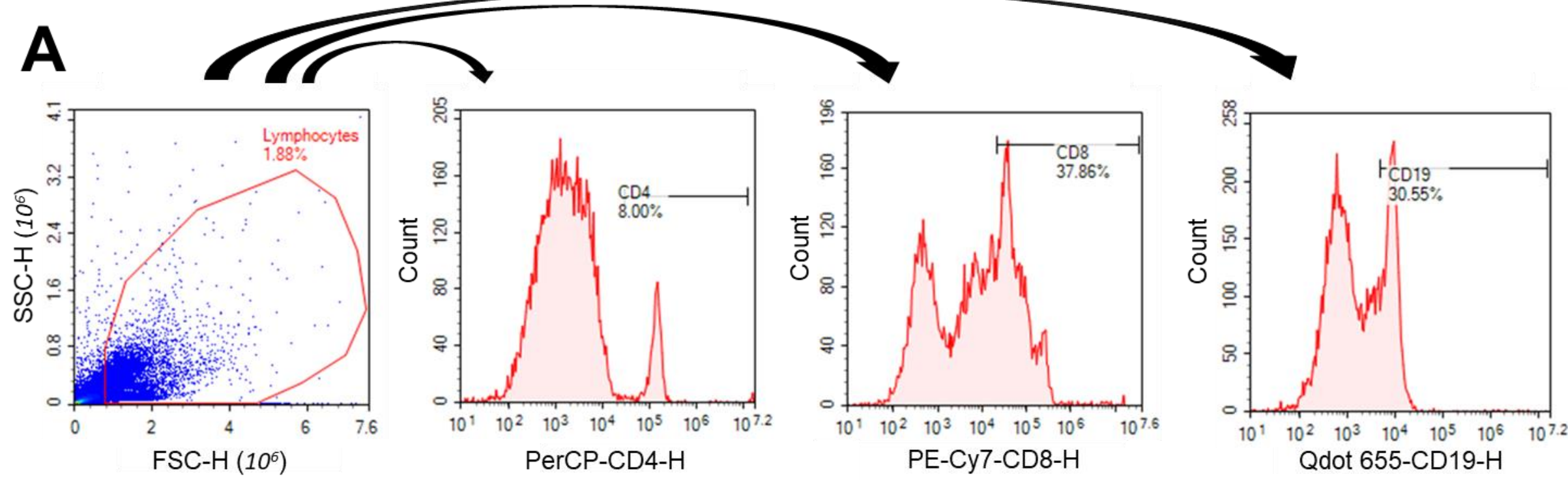

B
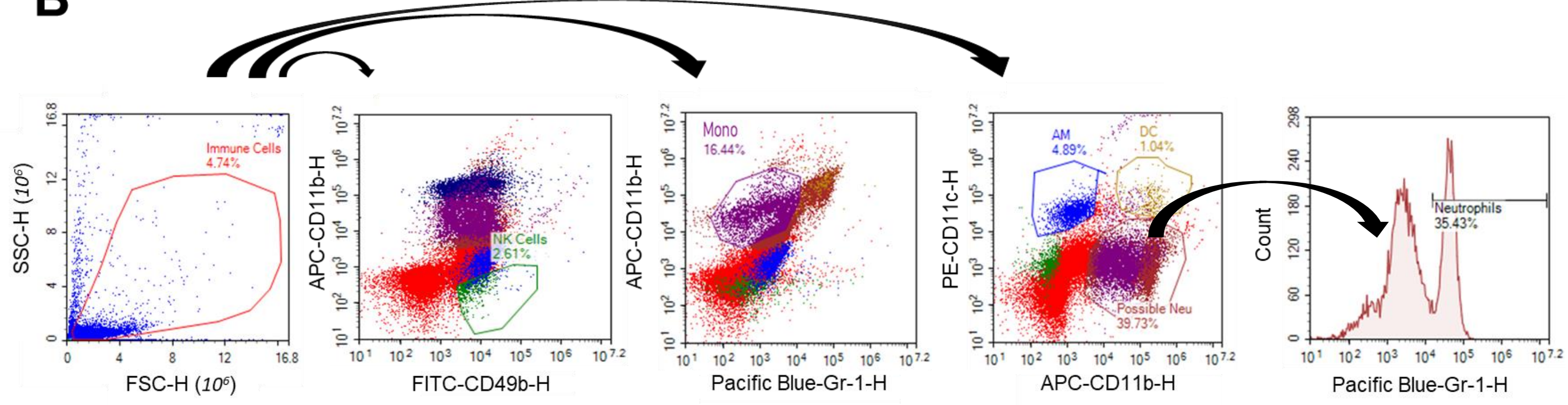

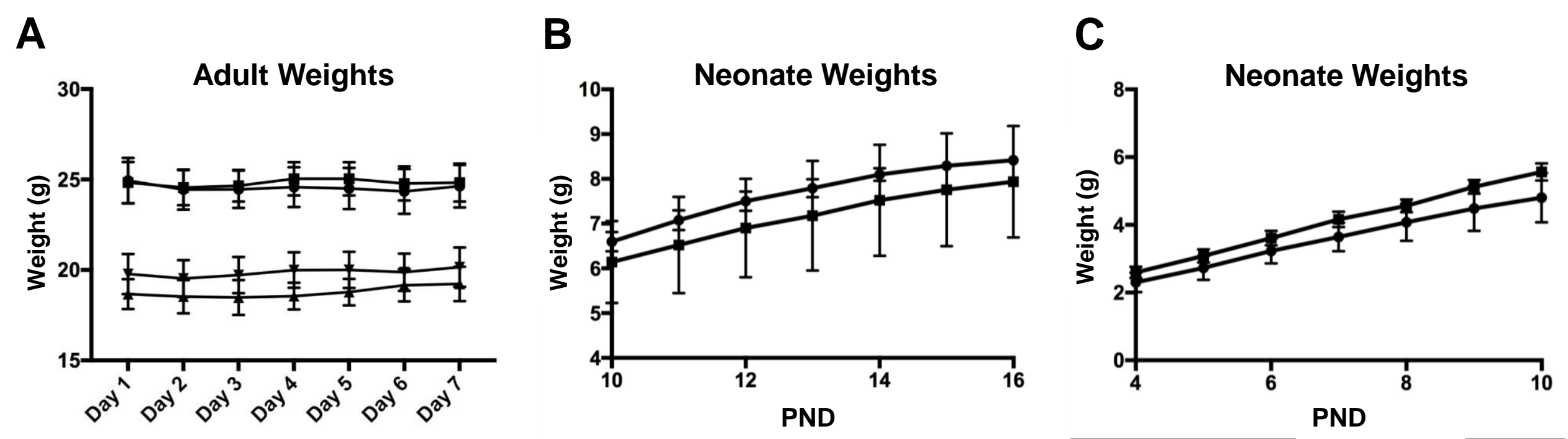

$\rightarrow-$ COIAM
- CPFIAM
+ COIAF
$\rightarrow$ CPFIAF
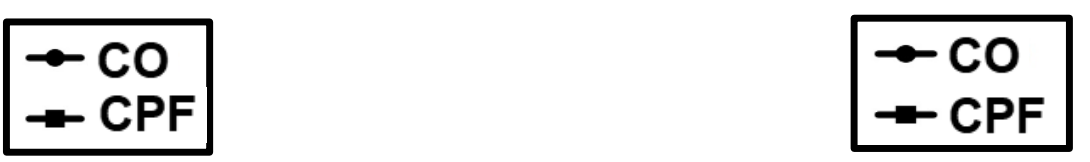
A

Neonatal brain AChE activity (WT mice)

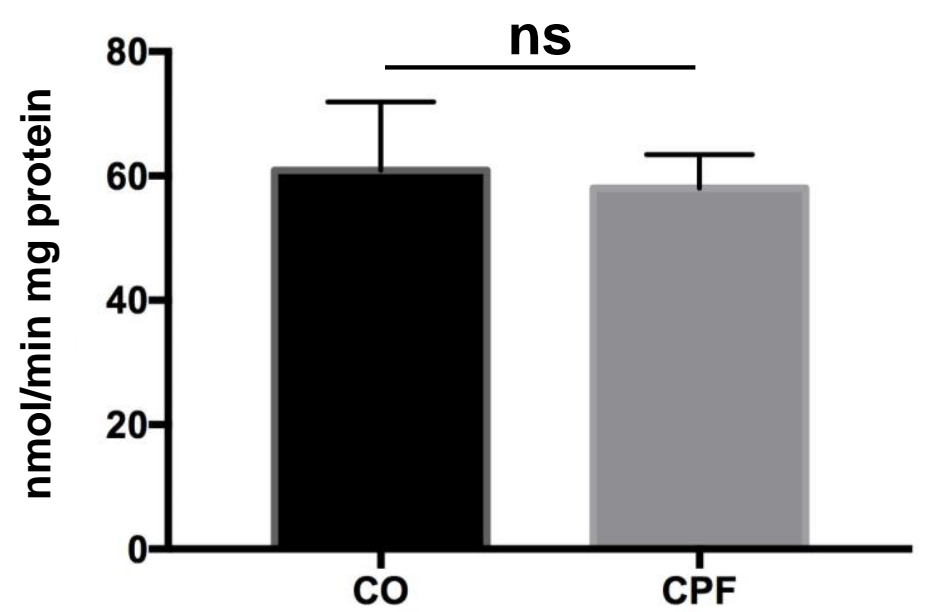

C Neonatal brain AChE activity (WT and Ces1d ${ }^{-/}$mice)

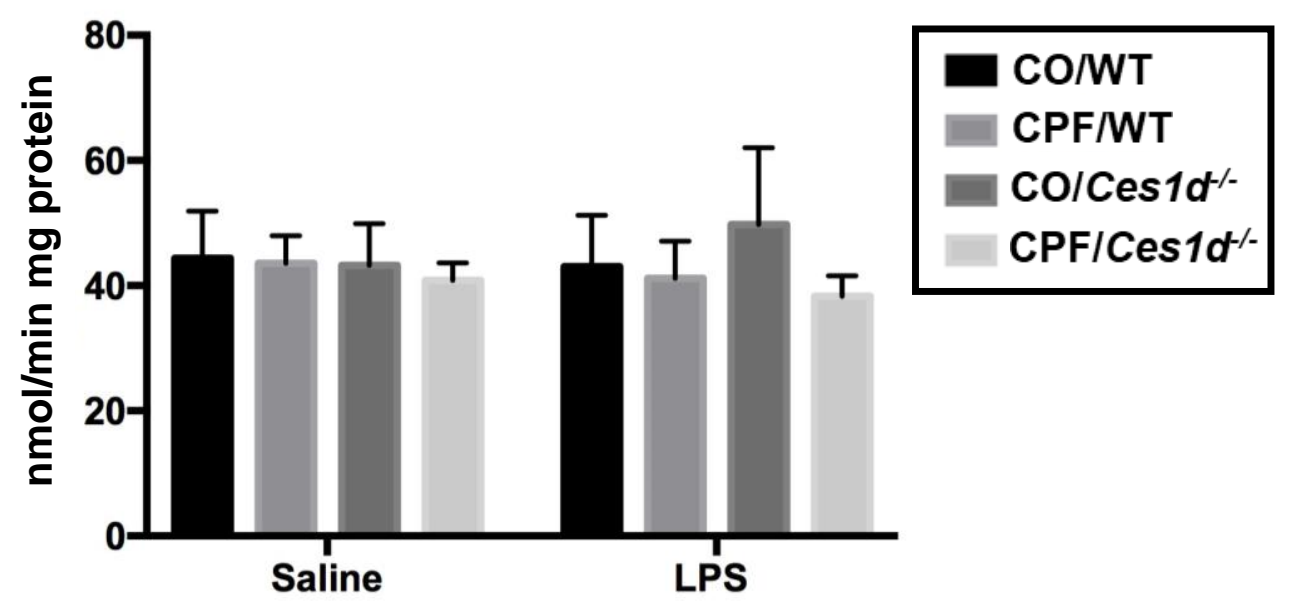

B

Adult female brain AChE activity (WT mice)

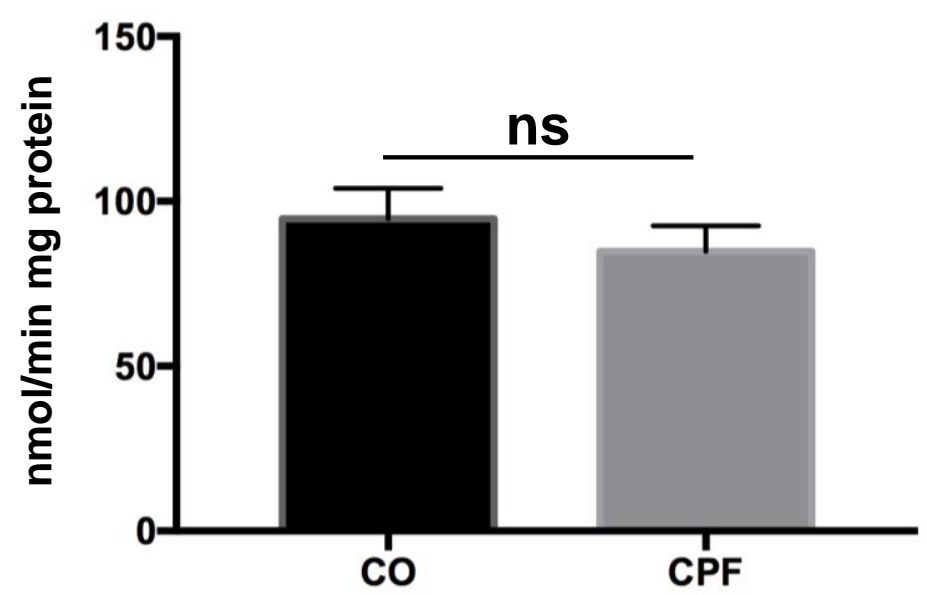

D Adult brain AChE activity (WT and Ces1d ${ }^{-/}$mice)

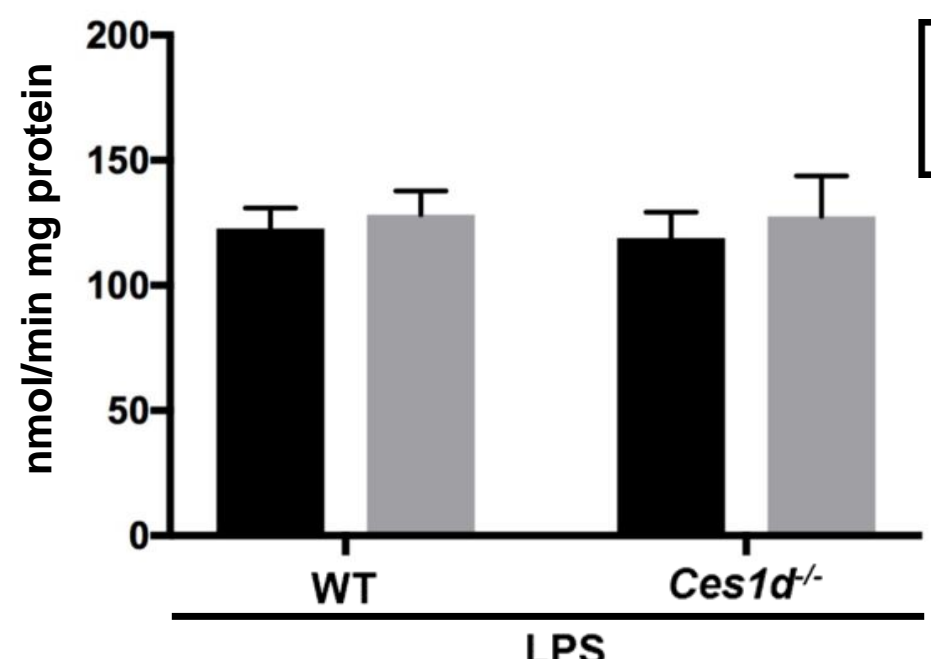

CO/LPS CPF/LPS 
Lung AChE

E

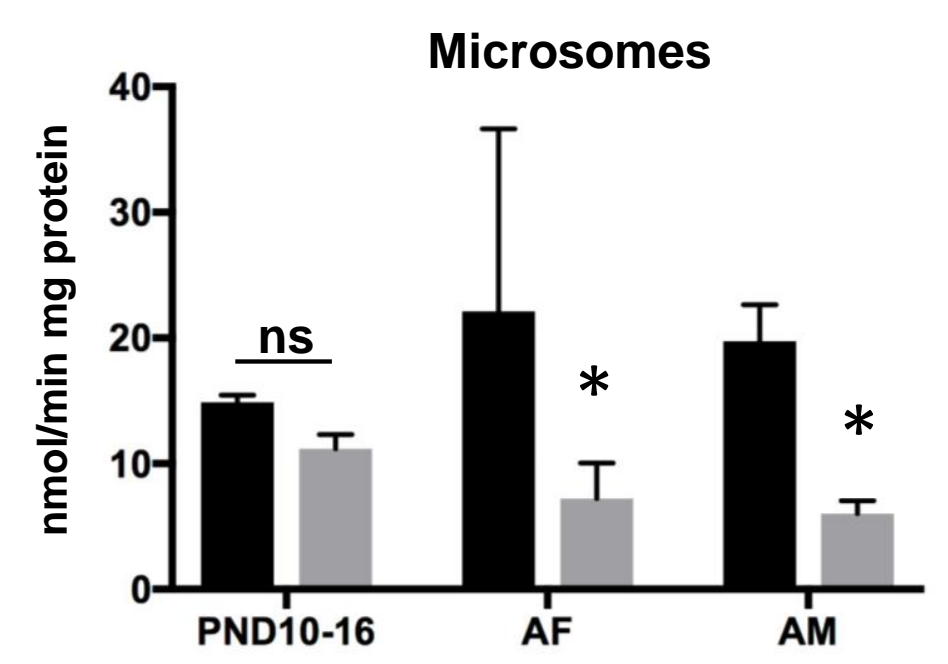

G

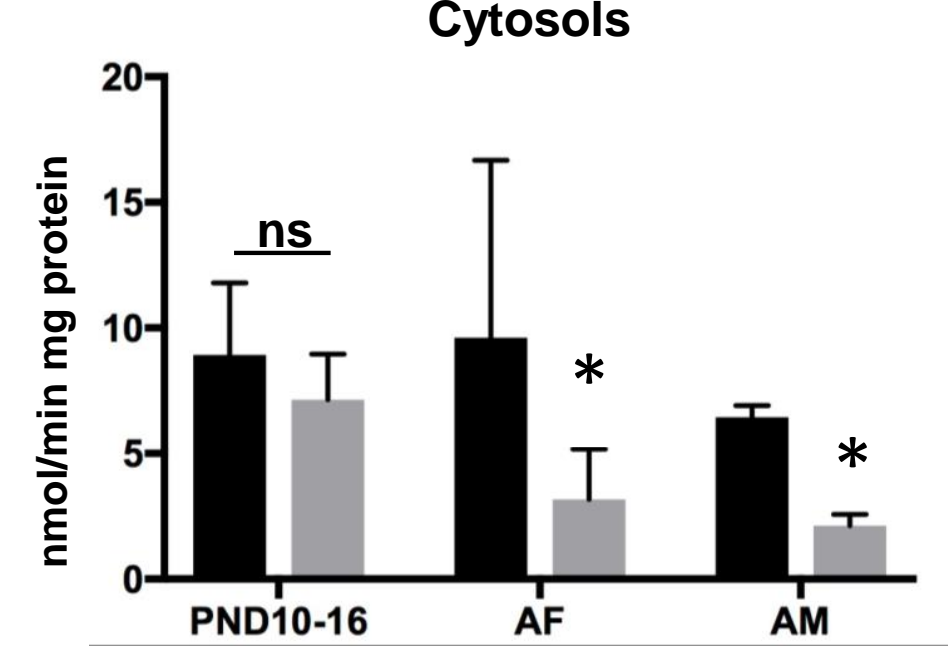

Lung BChE
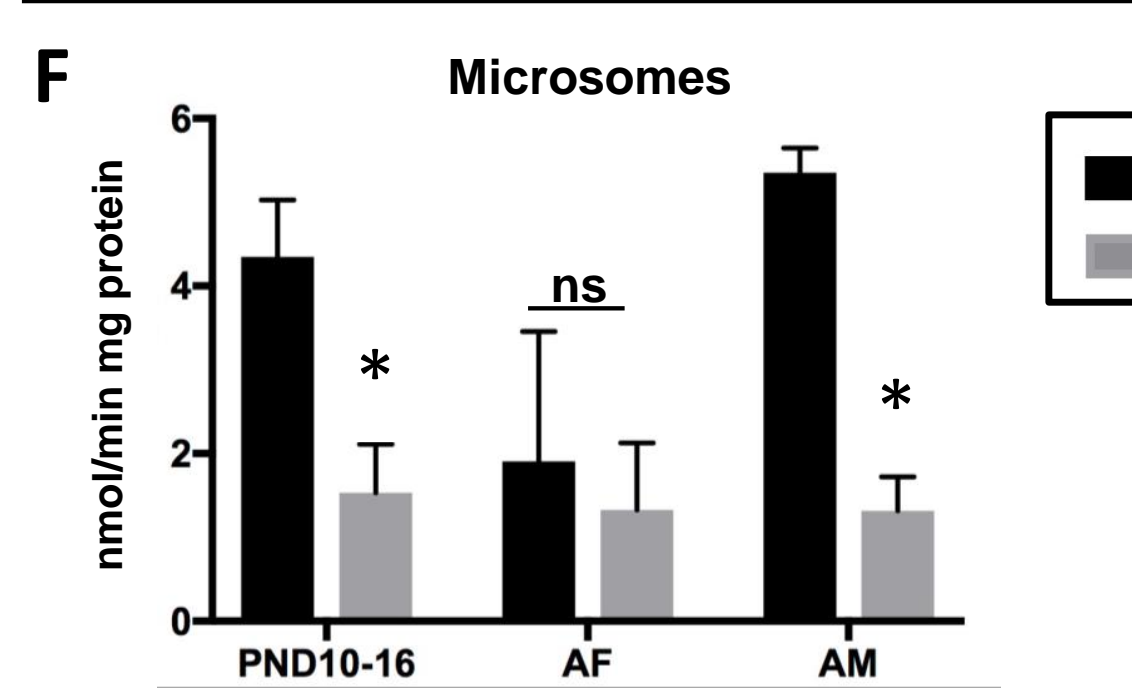

H Cytosols

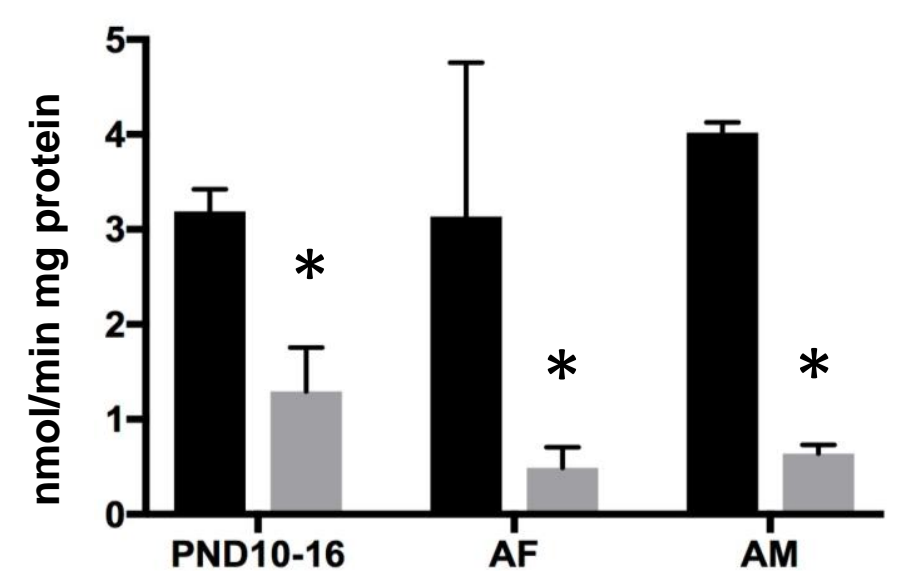




\section{Supplementary Figure 4}

A

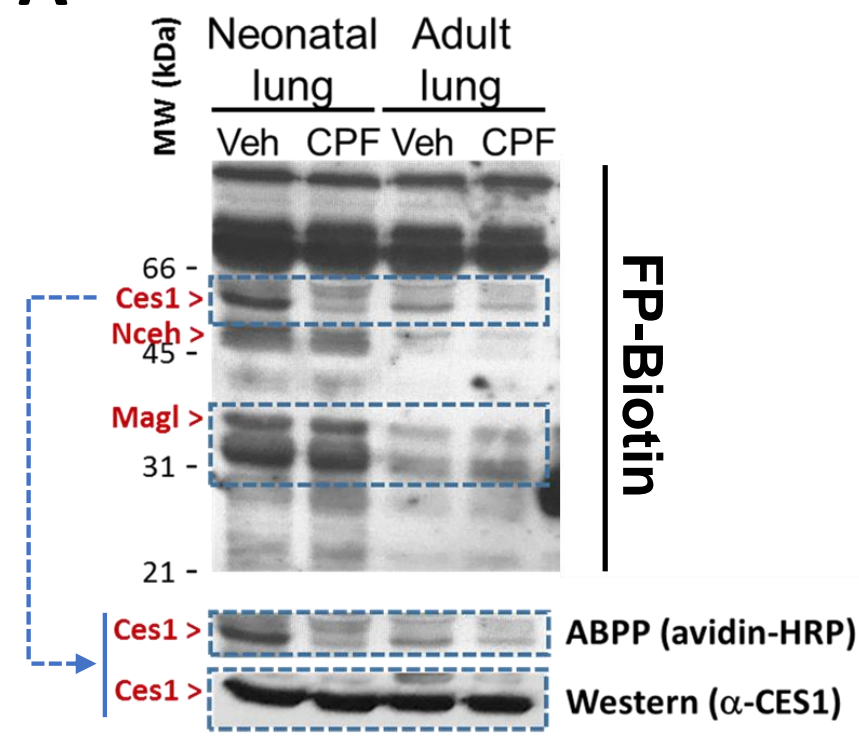

B

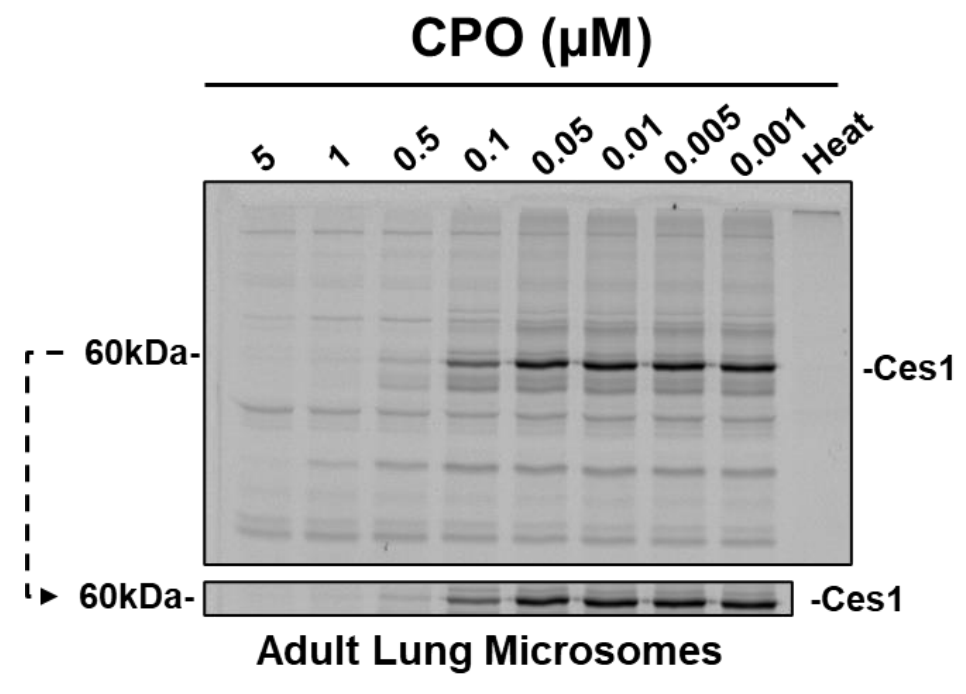

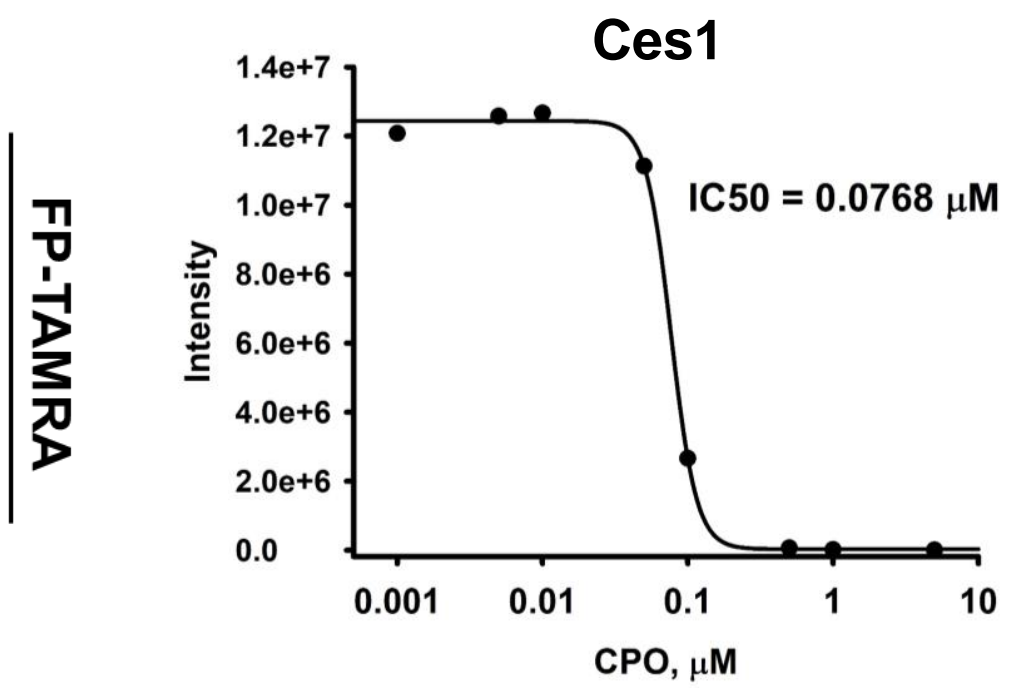




\section{Supplementary Figure 5}

A

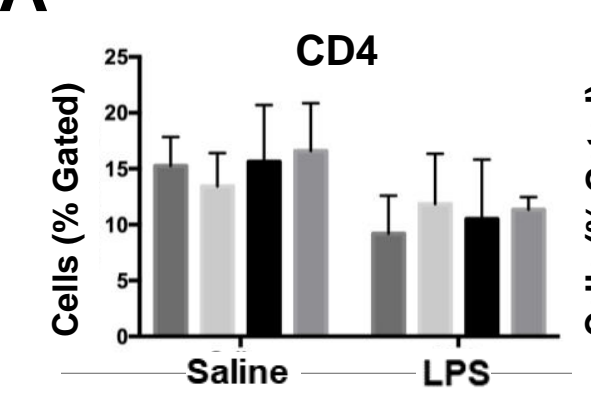

Neonate (WT and Ces1d ${ }^{-/}$)

C
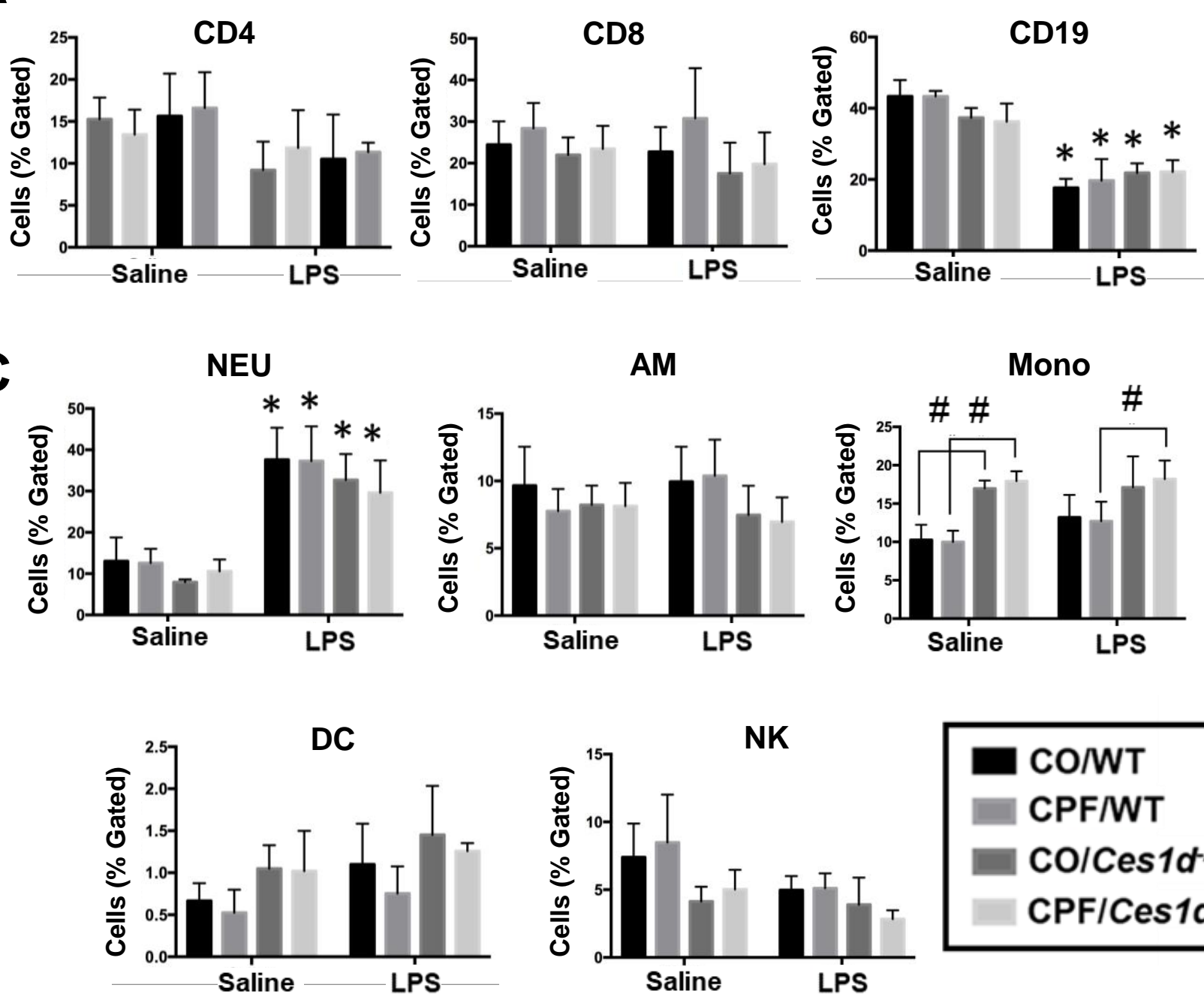

B
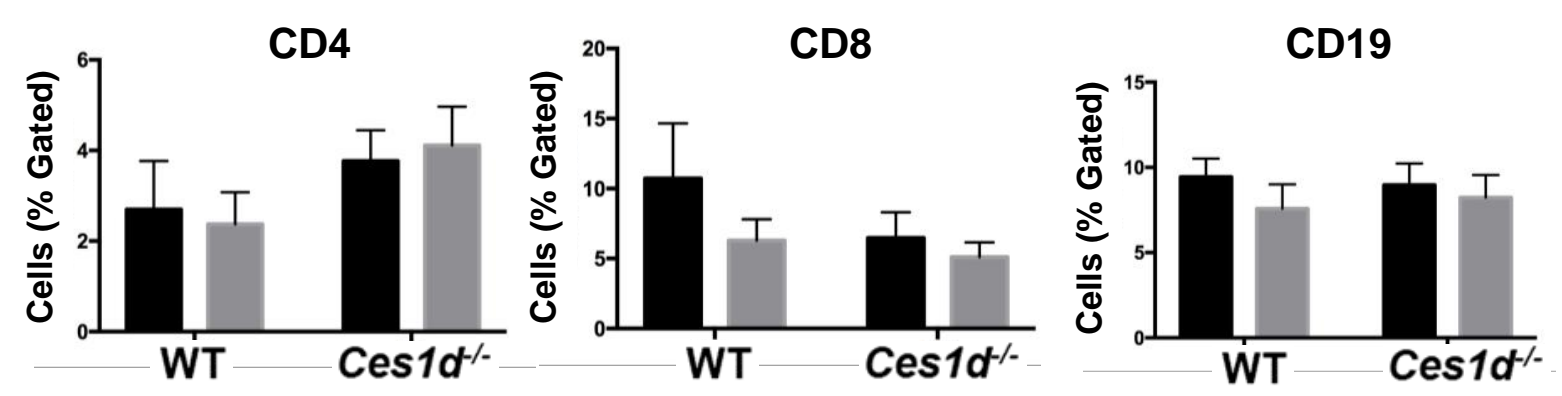

D
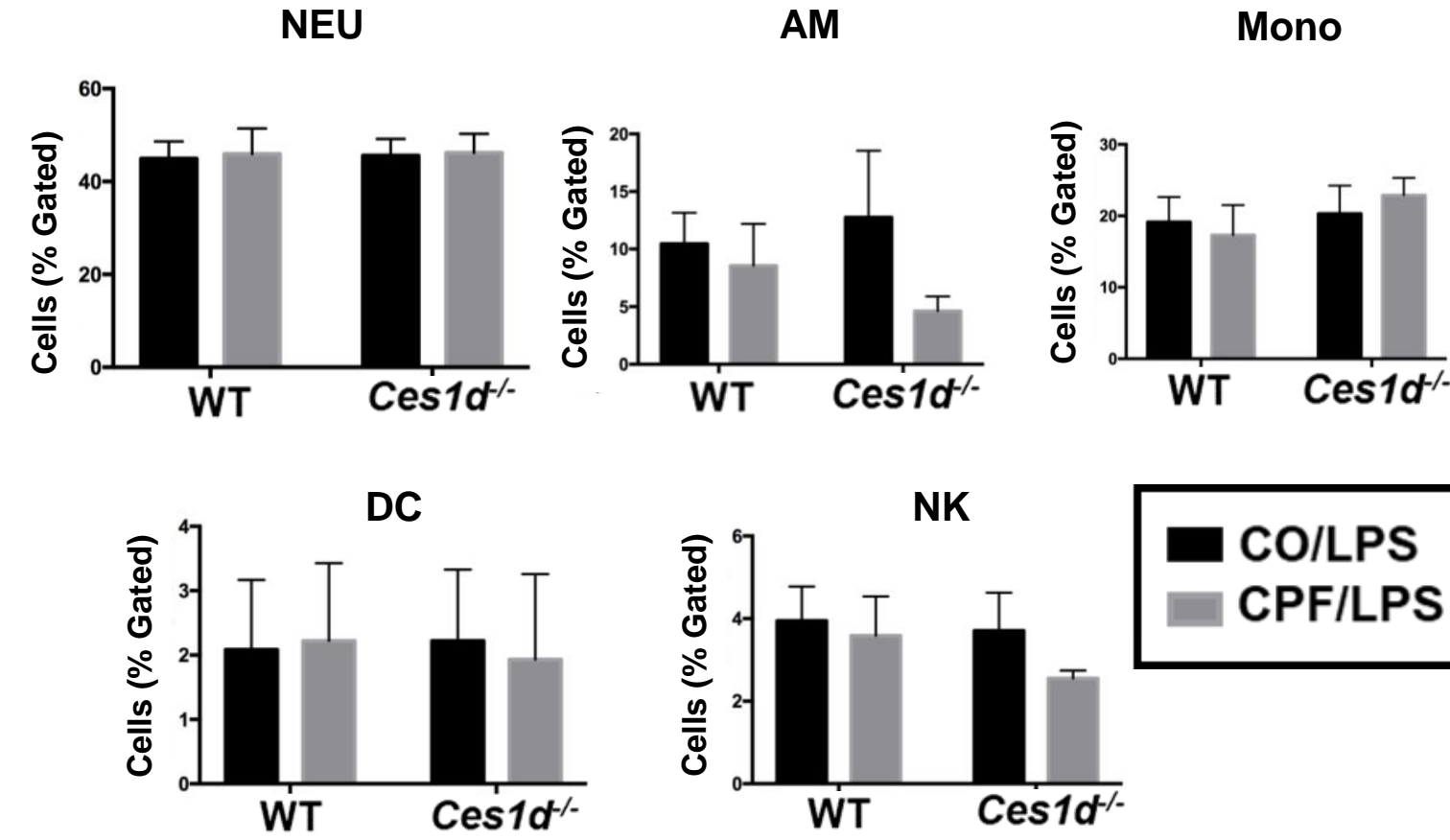


\section{Supplementary Figure 6}

RT-qPCR

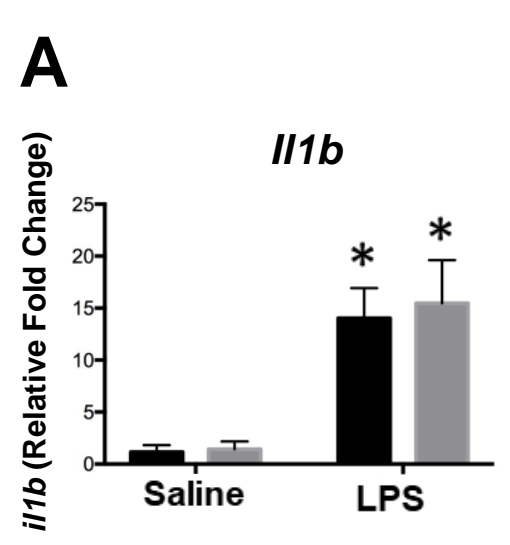

B

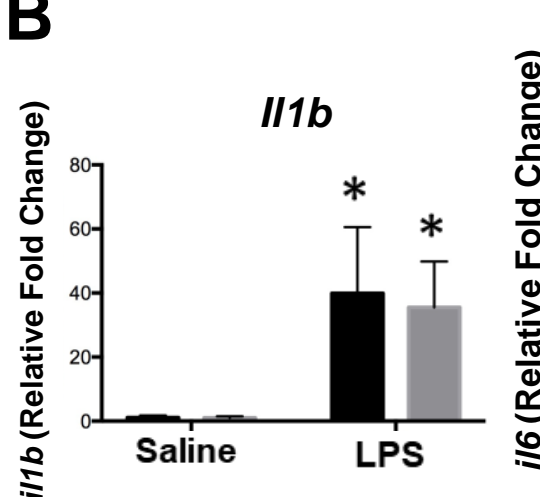

C

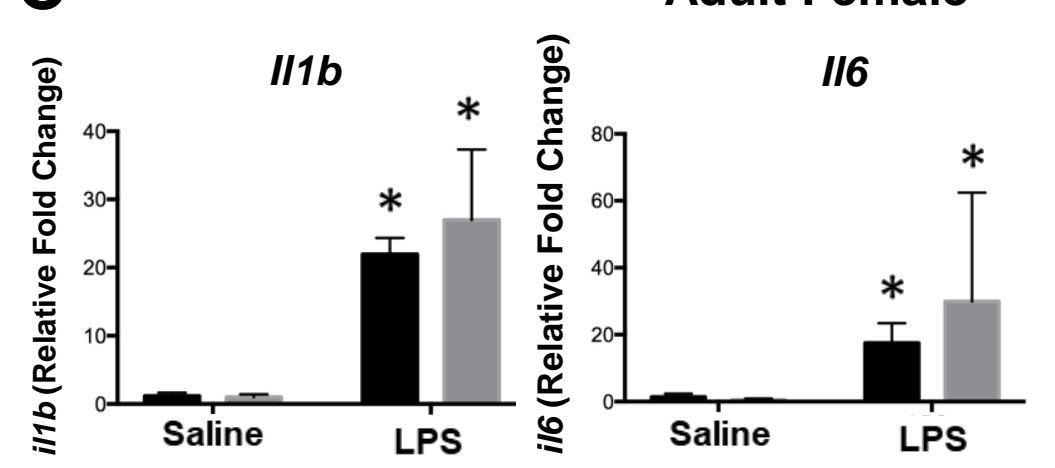

Neonate

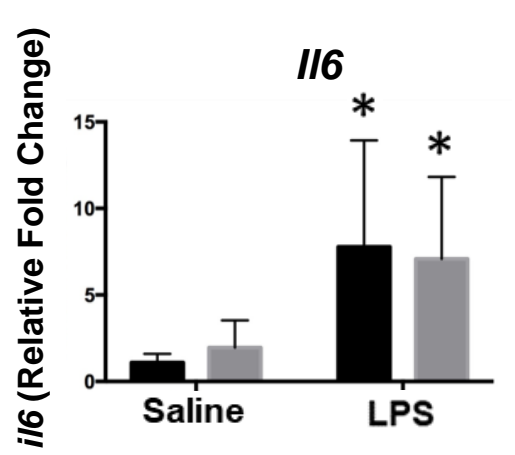

Adult Male
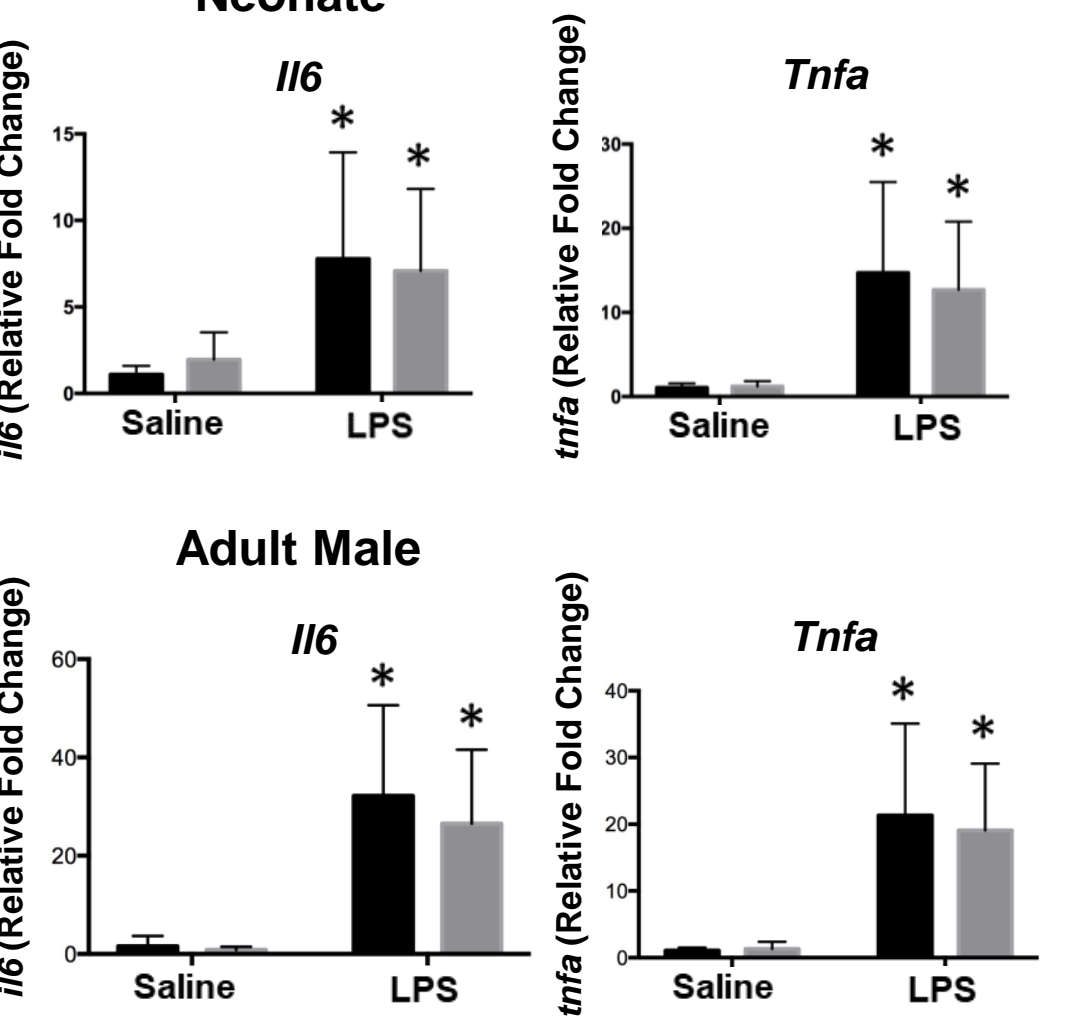

E
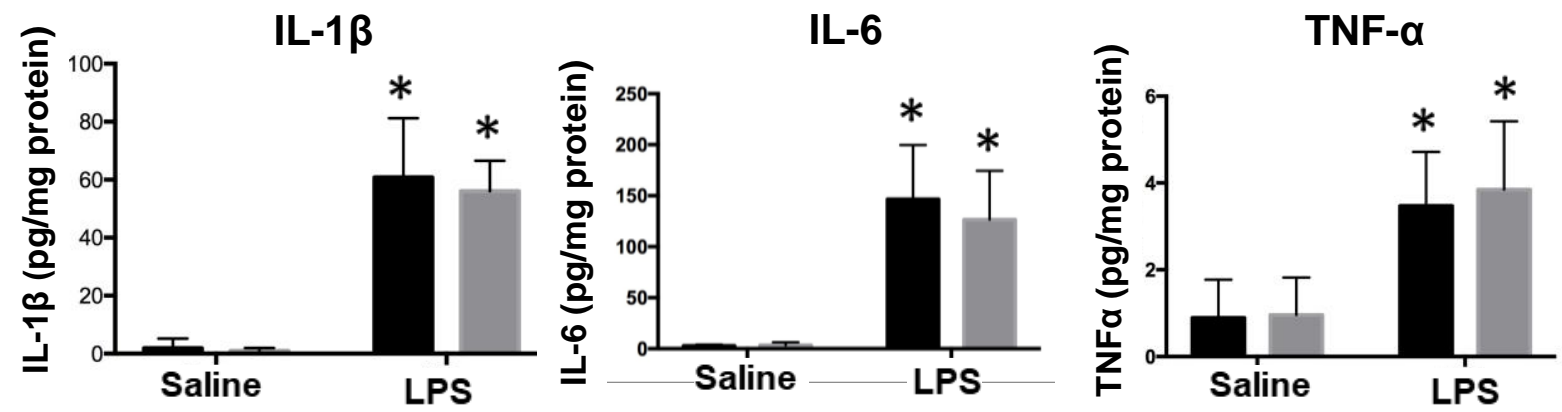

TNF- $\alpha$
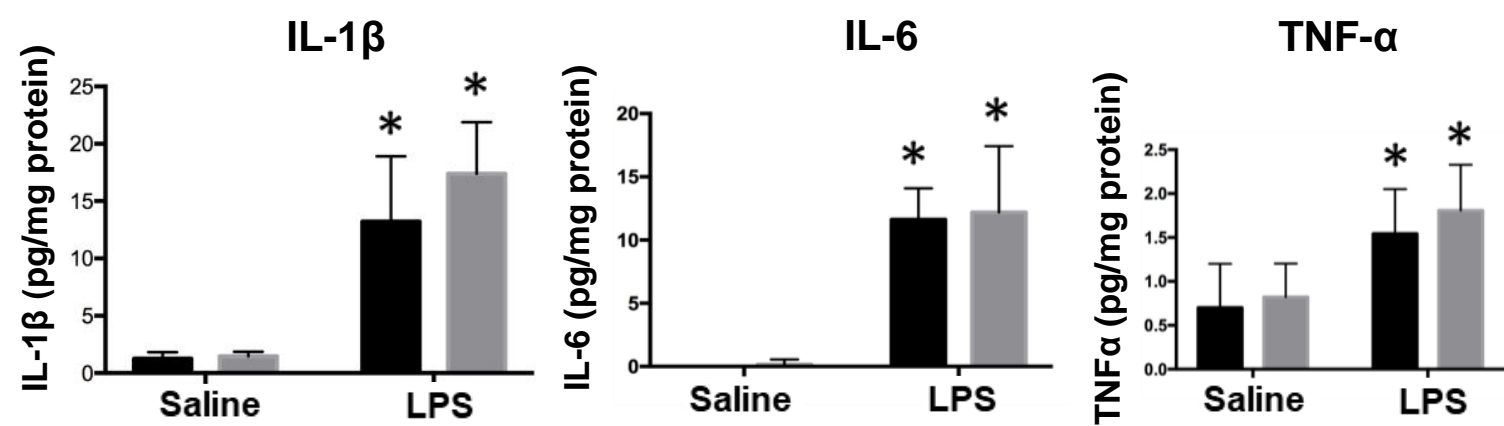

Adult Male
F Adult Female

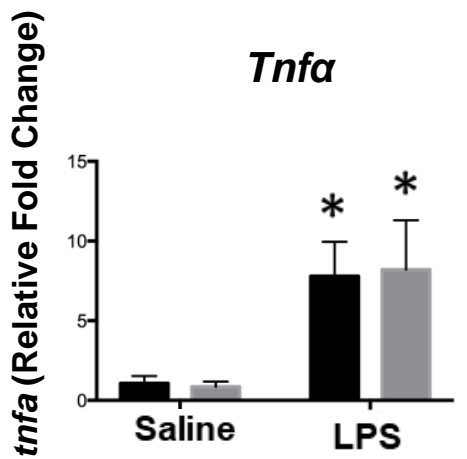




\section{Cytokines}
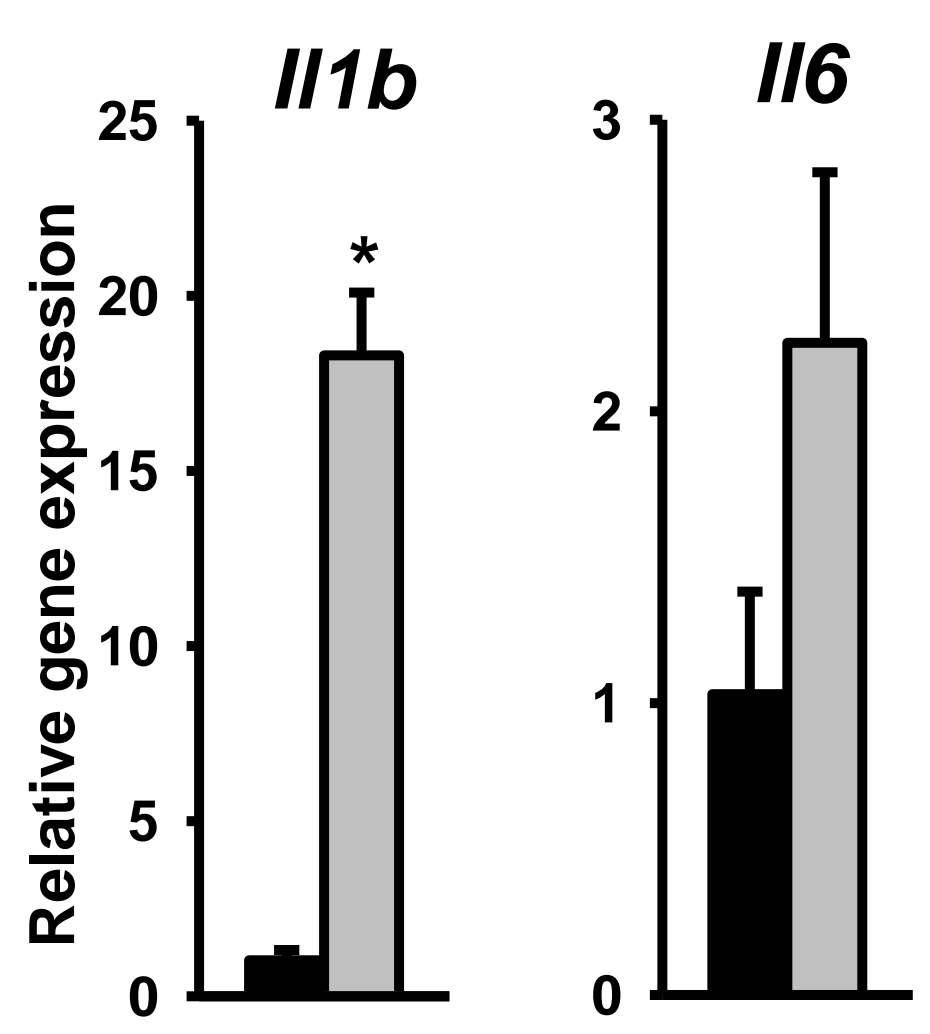

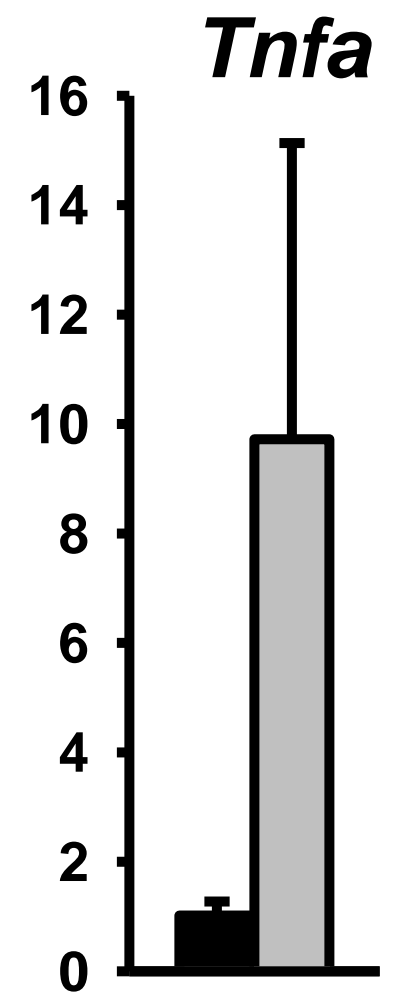

Ces isoforms

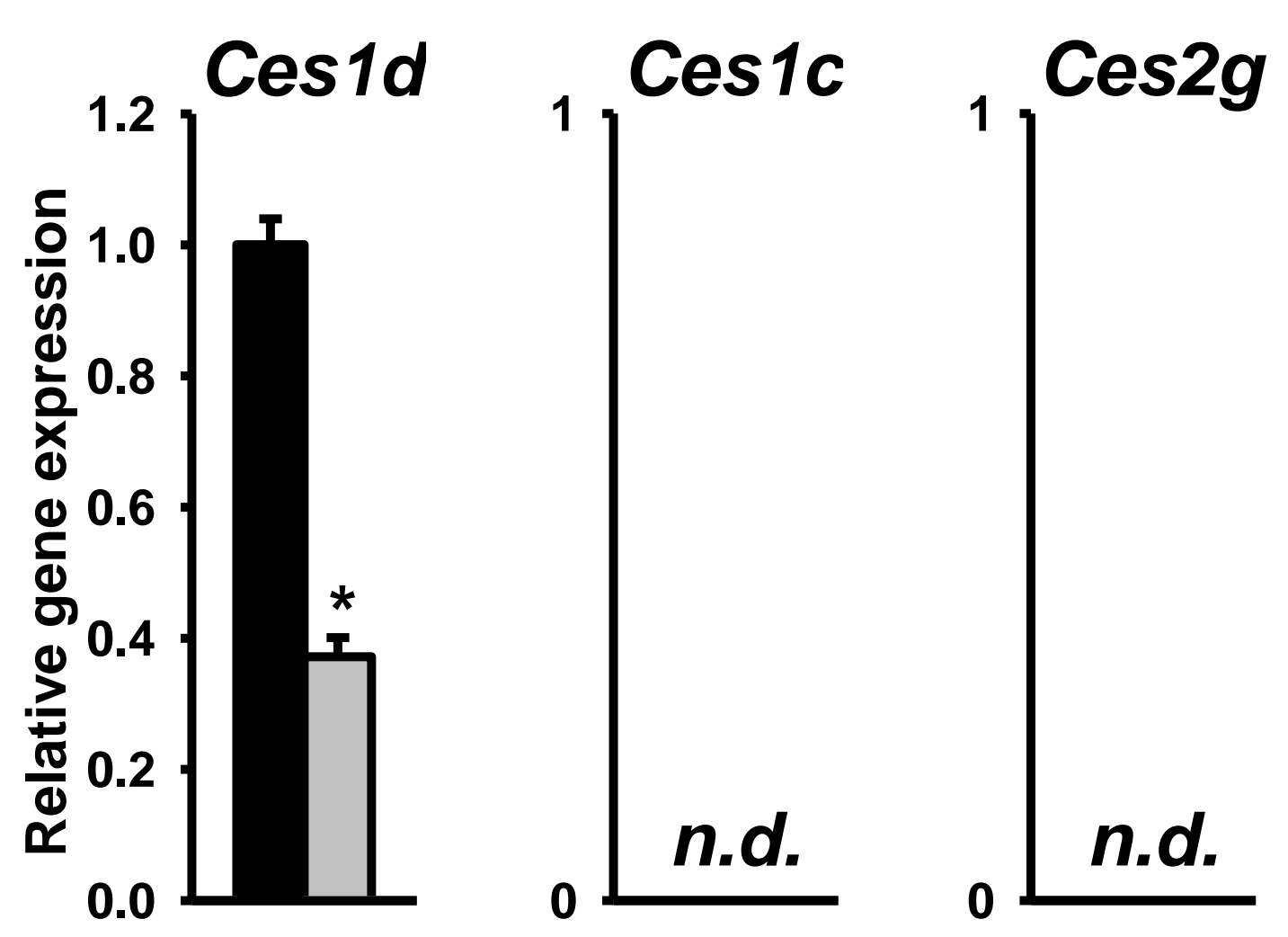


A
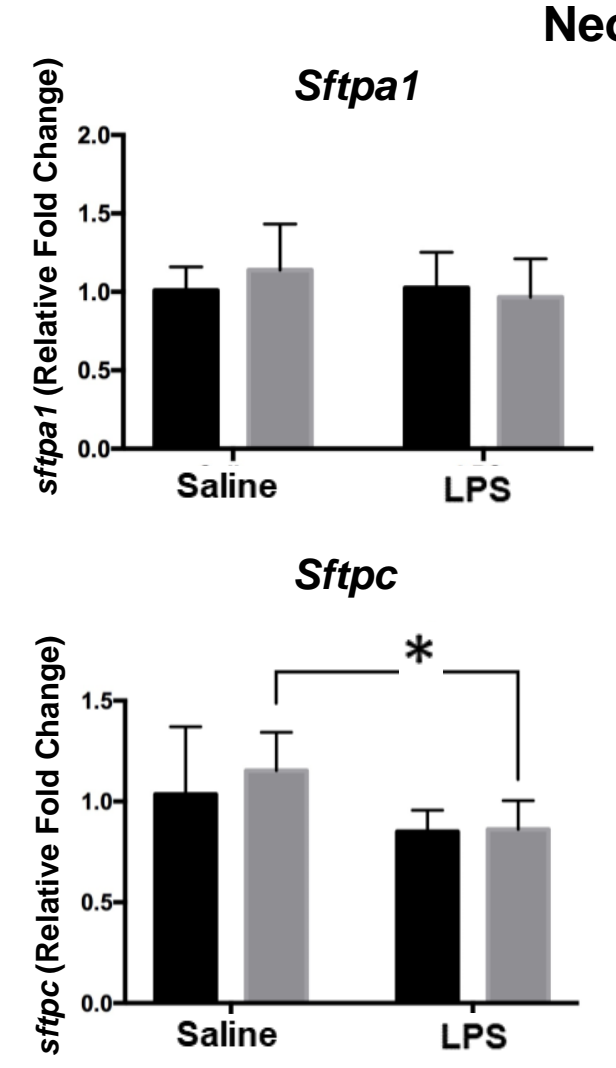

Neonate
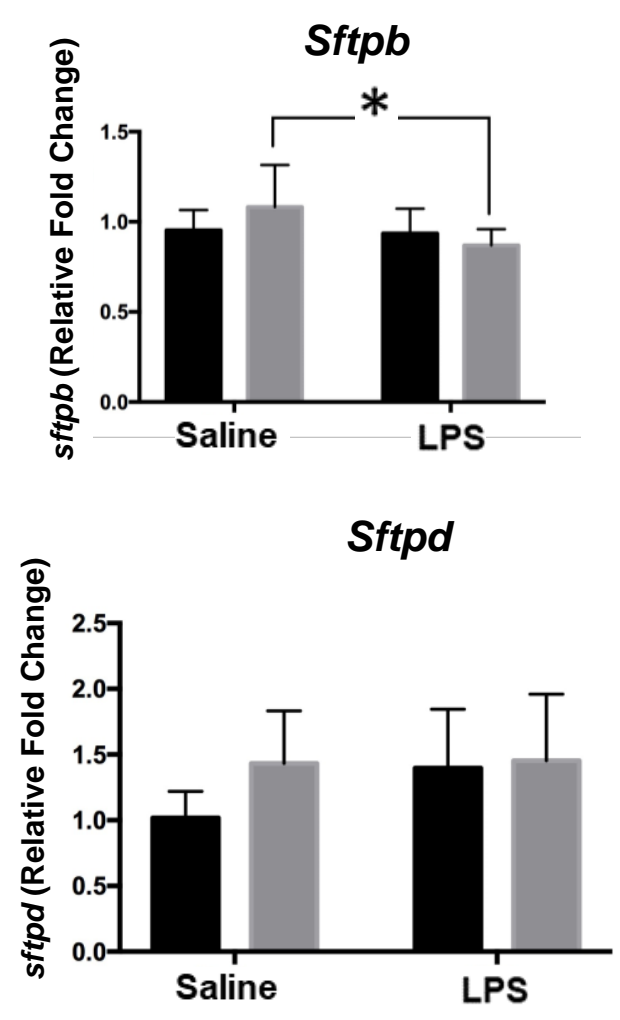

B
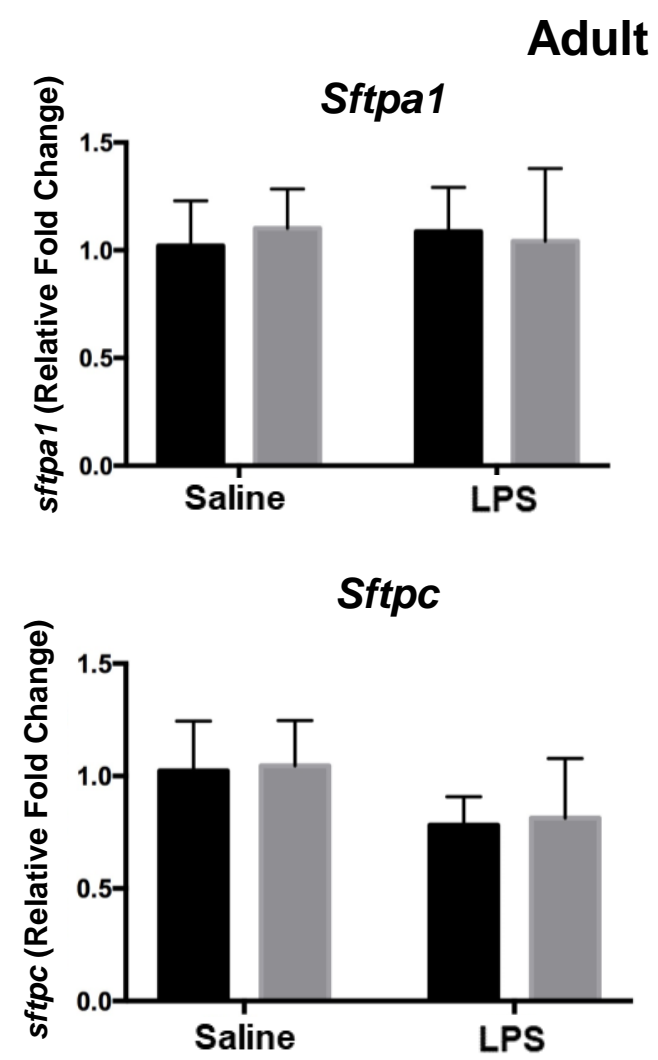

Adult Male
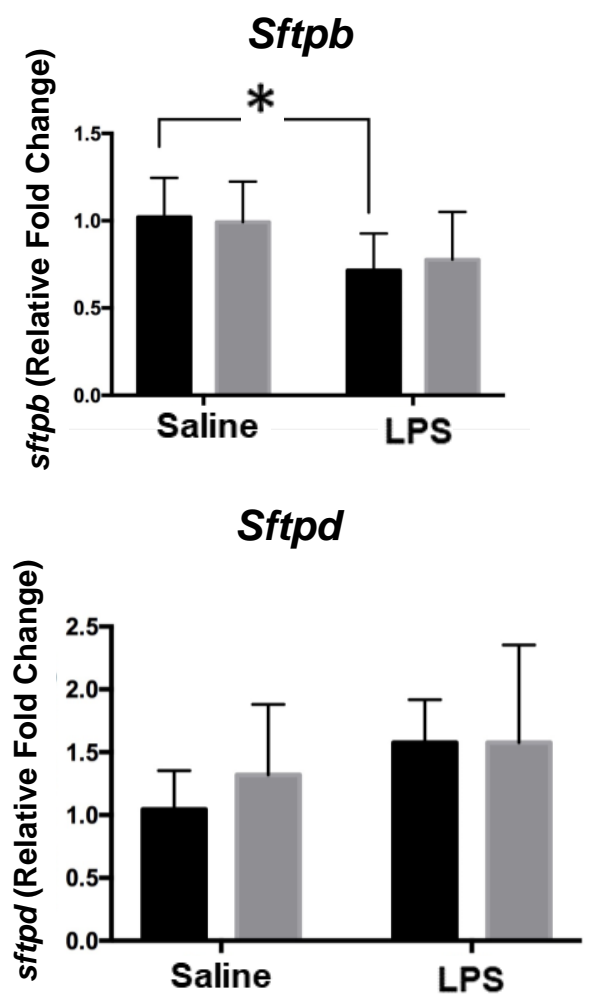


\section{Supplementary Figure 9}

A
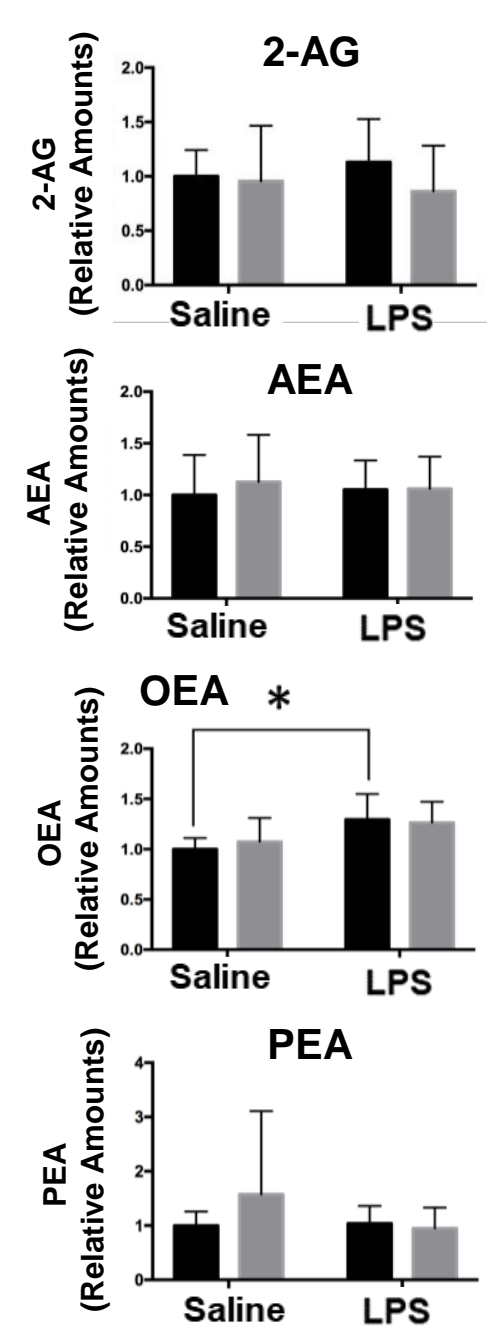

Neonate
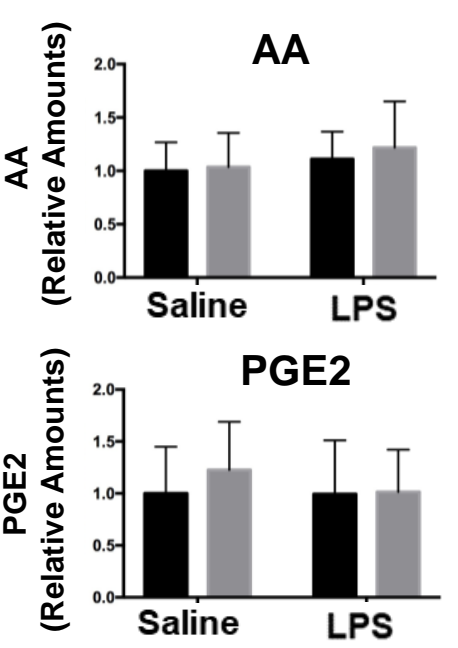

PGD2
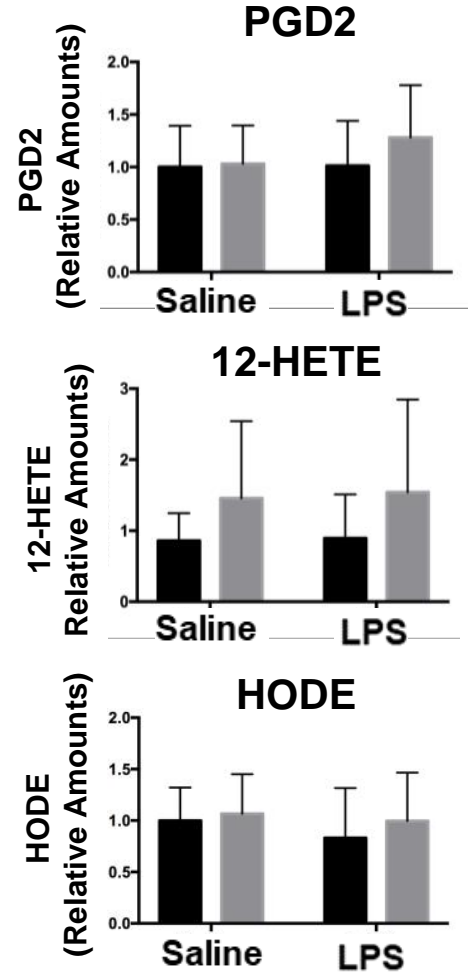

B
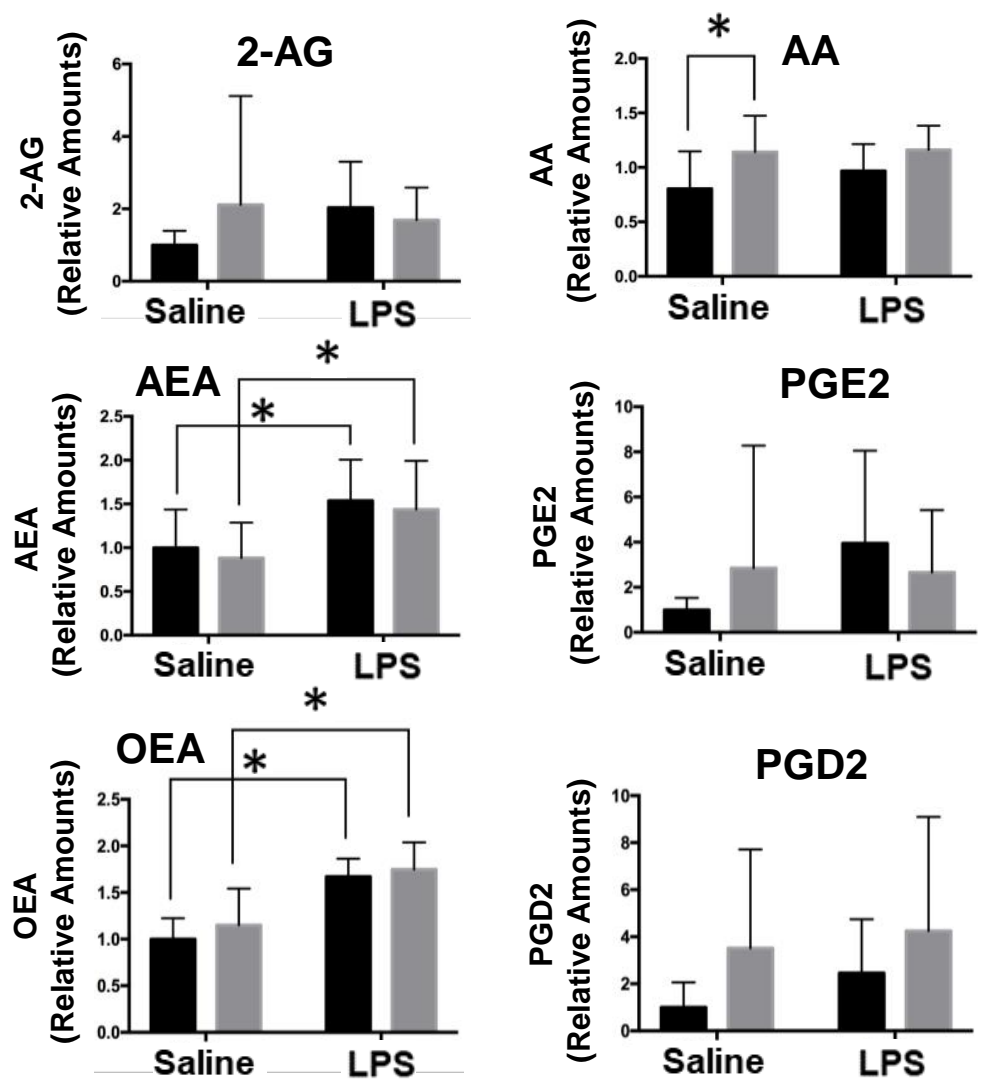

CO

CPF

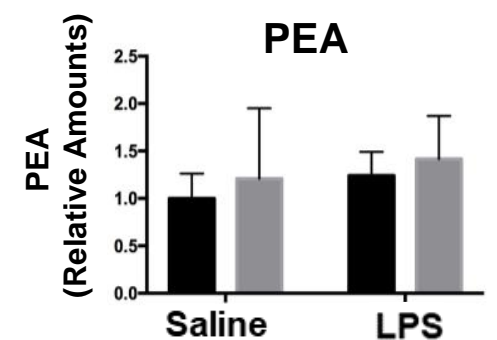

Adult Male

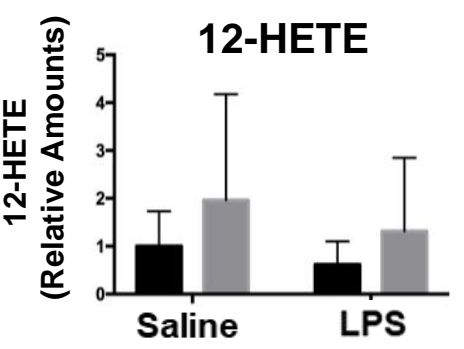

HODE

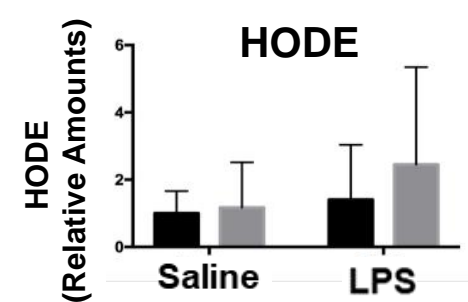




\section{Supplementary Figure 9}

C

Neonate (WT and Ces1 $\mathrm{d}^{-/ /}$)
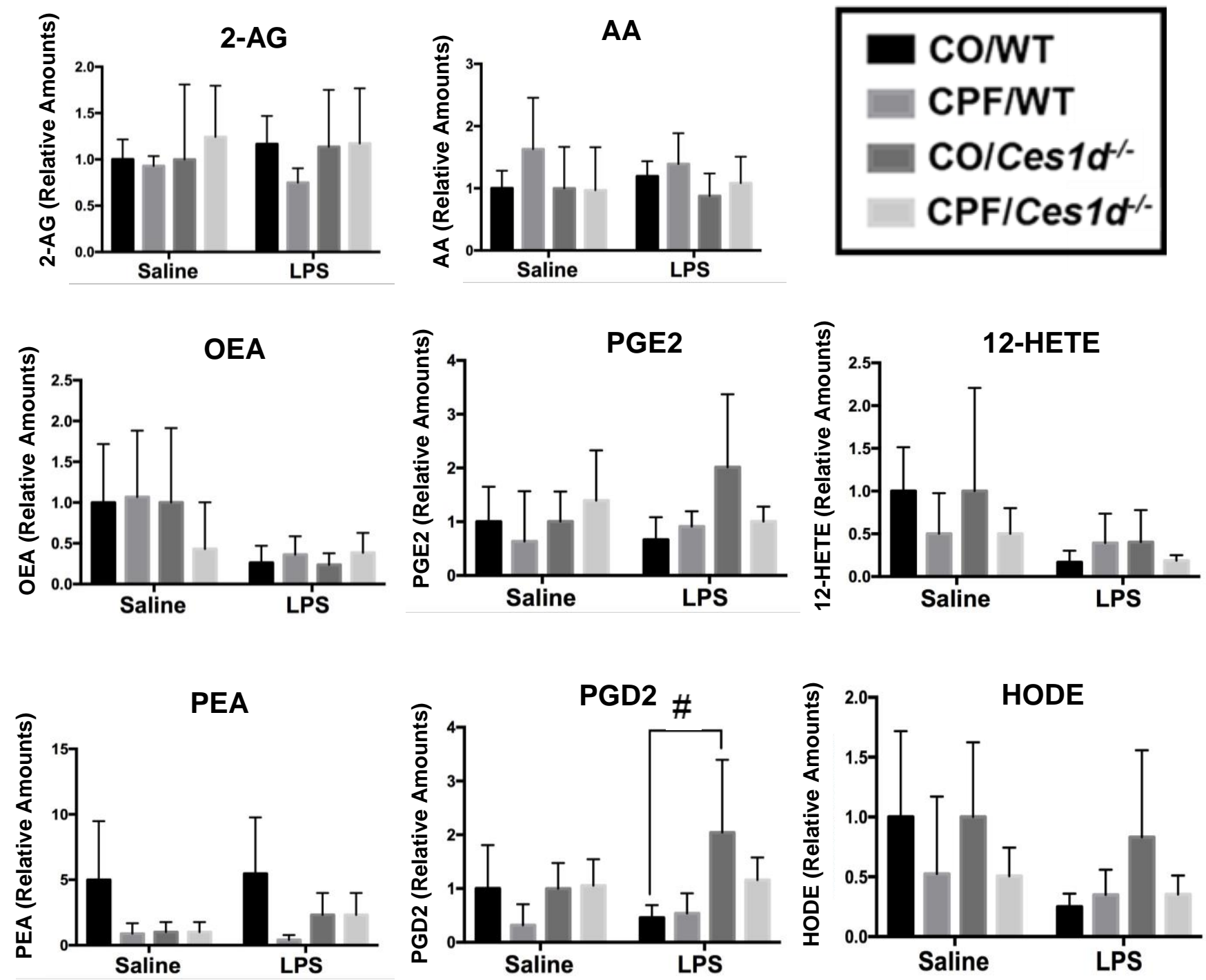

D Adult Male (WT and Ces1d ${ }^{-/}$)

2-AG

AA
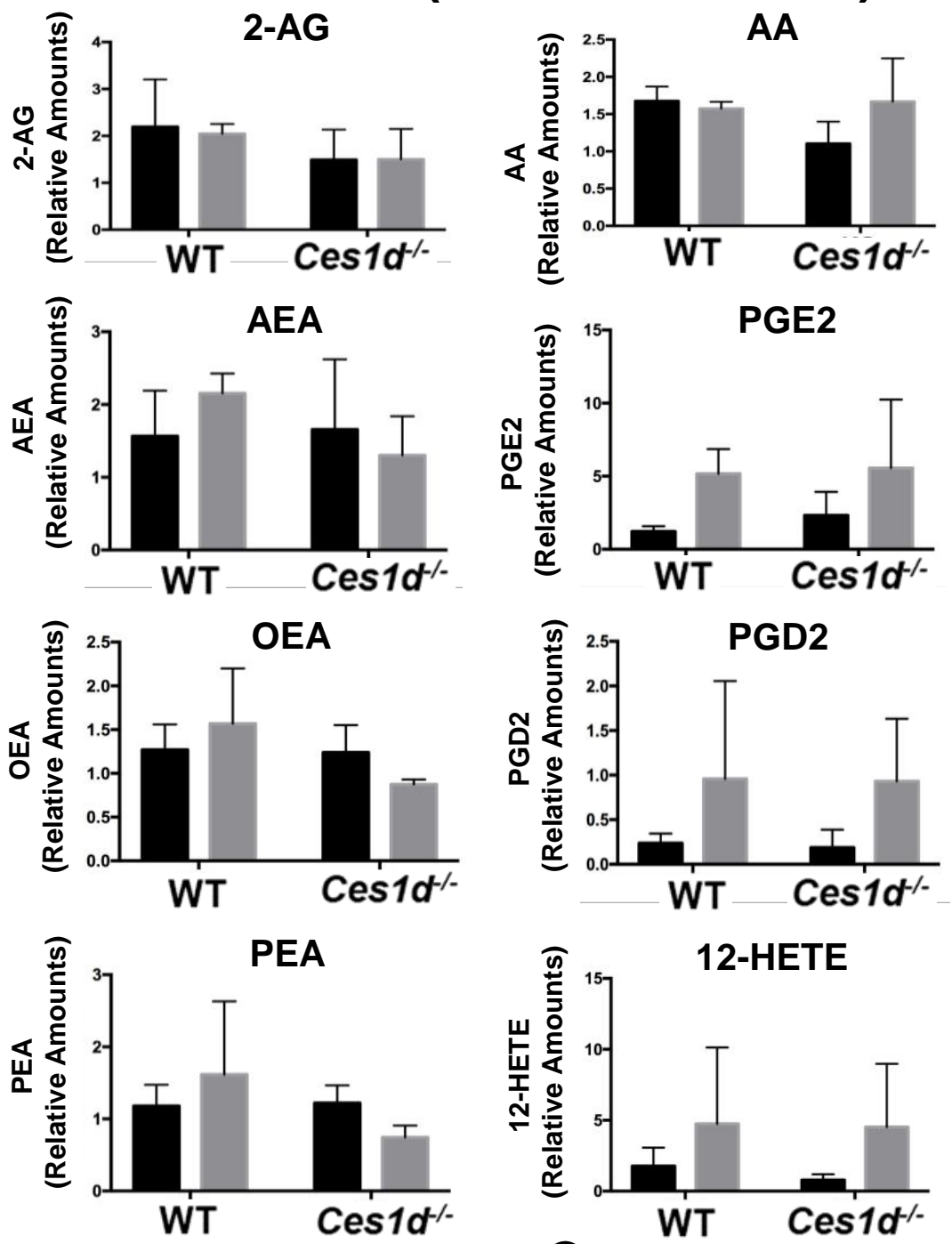

CO/LPS CPF/LPS

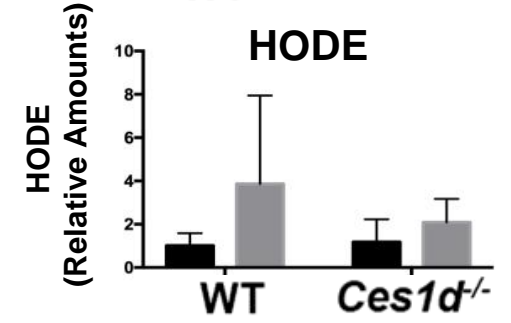

